\title{
Distribution of Oral Submucous Fibrosis Cases and Malignant Transformation Rate among Bhutanese Patients Treated at Jigme Dorji Wangchuck National Referral Hospital, Bhutan
}

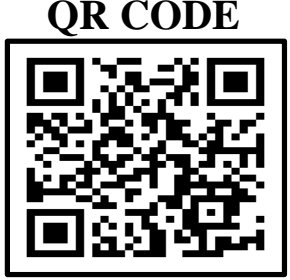

\section{PRATAP SINGH TAMANG', GYAN PRASAD BAJGAI', HARI PRASAD POKHREL*2(D}

BACKGROUND: Oral Submucous Fibrosis (OSMF) is a chronic, insidious, scarring disease of the mouth often involving the palate, oro-pharynx, pharynx, esophagus, tongue and the buccal mucosa which leads to ulceration, blanching and ultimately limited mouth opening. The aim of the study is to describe the age, gender and district-wise distribution of oral submucous fibrosis cases and to assess the malignant transformation rate among the patients with oral submucous fibrosis who were treated at Jigme Dorji Wangchuck National Referral Hospital, Thimphu, Bhutan. MATERIALS AND METHOD: This is a descriptive retrospective study. The patients were clinically diagnosed by examining their mouth and by measuring their mouth opening (Inter-incisal height). Patients who had less than 3 fingers mouth opening and diagnosed as Oral submucous fibrosis (OSMF) during these three-year period from 2018 to 2020 were considered for the study.

RESULTS: There were 278 cases in total. Thimphu district had the maximum number of cases followed by Wangduephodrang and Samtse. Gasa and Haa districts had the minimum cases. More males were affected than females. The malignant transformation rate among these patients was $4.3 \%$.

CONCLUSION: Thimphu district had the highest proportion of OSMF cases and was almost equally distributed among genders. Over $90 \%$ of the patients reported improvement without surgery while the malignancy transformation rate was $4.3 \%$. The study recommends conducting screening in districts with high burden of OSMF cases for early diagnosis and treatment.

KEYWORDS: Oral Submucous Fibrosis, Distribution, District, Bhutan

\section{INTRODUCTION}

Oral Submucous Fibrosis (OSMF) is a chronic, insidious, scarring disease of the mouth often involving the palate, oro-pharynx, pharynx, esophagus, tongue and the buccal mucosa which leads to ulceration, blanching and ultimately limited mouth opening. Epidemiological data and intervention studies suggest that betel nut and its products are the main etiological factors for development of OSMF. ${ }^{1}$ Other factors are chillies, lime, tobacco, nutritional deficiencies such as iron and zinc, immunological disorders, collagen disorders, GERD, smoking or chewing tobacco, alcohol and certain syndromic diseases. ${ }^{1-4}$ OSMF is a precancerous condition which has the potential to turn into cancer. It has one of the highest rates of malignant transformation among potentially malignant oral lesions and conditions. ${ }^{5}$

Mouth opening is restricted in this disease along with pain and burning sensation in the mouth. In most of the cases, these are the only reasons patients visit hospital for care and support. The primary aim of the treatment is to increase mouth opening and rendering them asymptomatic while eating. ${ }^{6}$ The normal range of mouth opening differs from person to person, varying between $40-60 \mathrm{~mm}$ with an average between $35-55$ $\mathrm{mm}$ which is equal to the width of three fingers. ${ }^{7,8}$ In general, males display greater mouth opening than females. ${ }^{7,8}$ There are numerous classifications used for classifying the severity of mouth opening. Passi D et al., classified the mouth opening as; Grade I- mouth opening up to $35 \mathrm{~mm}$, Grade II- mouth opening between $25-35 \mathrm{~mm}$, Grade III- mouth opening between $15-25 \mathrm{~mm}$ and Grade IV where mouth opening is less than $15 \mathrm{~mm}$ to nil. ${ }^{9}$

The South East Asian region has a higher prevalence of OSMF compared any other part of the world which can be attributed to habit of chewing betel and betel products. $^{1,2}$ Betel wrapped in betel leaf along with different spices is consumed in parts of India, Bangladesh, Nepal, Pakistan and Thailand. In Bhutan, it is customary to offer betel during functions and festivals, which is chewed by wrapping it in a betel leaf along with lime. However, there is limited data about the topic in Bhutan. Thus, this study describes the age, gender and district wise distribution of oral submucous fibrosis cases and malignant transformation rate among the patients with oral submucous fibrosis 
who were treated at the dental department of JDWNRH from 2018 to 2020.

\section{MATERIALS AND METHOD}

This is a retrospective study conducted at Jigme Dorji Wangchuck National Referral Hospital, Bhutan. Jigme Dorji Wangchuck National Referral Hospital (JDWNRH) is the apex hospital in the country and caters to all complex medical, surgical and dental cases referred in from district hospitals. Patients were clinically diagnosed by examining their mouth and by measuring their mouth opening (Inter-incisal height). Patients who had less than 3 fingers mouth opening and diagnosed as Oral submucous fibrosis (OSMF) during the three-year period from 2018 to 2020 were considered for the study. Malignant transformations were confirmed by biopsy and histopathological examinations. Radiographic examination including XRays and CT, MRI were also done in confirmed cancer cases to assess the involvement of other structures like the jaw, brain, neck and cervical lymph nodes. Ethical approval for the study was obtained from the Research Ethics Board of Health (REBH), Ministry of Health, Bhutan.

Data analysis: Data collected was double entered and validated using Epi-Data version 3.1 and analyzed using Microsoft Excel. The findings are presented as frequencies and percentages.

\section{RESULT}

There were a total of 278 OSMF cases recorded in the past three years. Over half $(54.7 \%)$ of the participants were male and a majority $(77 \%)$ of them in the age group 19-59 years (table 1 ).

\begin{tabular}{|c|c|c|c|}
\hline VARIABLE & CATEGORY & FREQUENCY & PERCENT \\
\hline \multirow{2}{*}{ GENDER } & Male & 152 & $54 \cdot 7$ \\
\hline & Female & 126 & $45 \cdot 3$ \\
\hline \multirow{2}{*}{ AGE } & $<18$ & 10 & 3.6 \\
(in years) & $18-59$ & 214 & 77.0 \\
\hline & $\geq 60$ & 54 & 19.4 \\
\hline
\end{tabular}

Table 1. Age and gender distribution of OSMF cases $(\mathrm{n}=\mathbf{2 7 8})$

Case distribution is presented in table 2. OSMF cases were present in all the twenty districts of Bhutan. Thimphu district had the highest proportion of cases $(14 \%)$ while Gasa had the lowest proportion (2.2\%).
Prognosis / Outcome of the patients is being presented in table 3. Majority (90.6\%) of the participants reported improvement without surgery while $4.3 \%$ had transformation to cancer.

\begin{tabular}{|c|c|c|}
\hline DISTRICT & FREQUENCY & PERCENT \\
\hline Thimphu & 39 & 14.0 \\
\hline Wangduephodrang & 28 & 10.0 \\
\hline Samtse & 17 & 6.1 \\
\hline Trashigang & 16 & $5 \cdot 7$ \\
\hline Mongar & 16 & $5 \cdot 7$ \\
\hline Trashiyangtse & 15 & $5 \cdot 3$ \\
\hline Punakha & 14 & 5.0 \\
\hline Chukha & 14 & 5.0 \\
\hline Pemagatshel & 13 & $4 \cdot 7$ \\
\hline Paro & 12 & $4 \cdot 3$ \\
\hline Trongsa & 11 & $3 \cdot 9$ \\
\hline Sarpang & 11 & 3.9 \\
\hline Tsirang & 11 & $3 \cdot 9$ \\
\hline Dagana & 11 & 3.9 \\
\hline Bumthang & 11 & 3.9 \\
\hline Lhuentse & 10 & 3.6 \\
\hline Samdrupjongkhar & 9 & 3.2 \\
\hline Zhemgang & 8 & 2.9 \\
\hline Haa & 6 & 2.2 \\
\hline Gasa & 6 & 2.2 \\
\hline $\begin{array}{l}\text { Table 2. District } \\
\text { ca }\end{array}$ & $\begin{array}{l}\text { e distributio } \\
(n=278)\end{array}$ & OSMF \\
\hline
\end{tabular}

\section{DISCUSSION}

Thimphu had the highest proportion of OSMF cases which can be attributed to larger population as Thimphu is also the capital of Bhutan. The malignancy transformation rate to cancer was $4.3 \%$. There are different studies suggesting malignant transformation rates of OSMF. According to one of the recent studies, it is seen that it has increased from $0.03 \%$ to $6.42 \%$ in India. ${ }^{1}$ According to Chourasia et al. the incidence of malignant transformation to oral squamous cell carcinoma in patients of untreated oral submucous fibrosis is $4.2 \% .^{10}$ The incidence of oral cancer concomitant with oral submucous fibrosis is found to be $25.77 \%$ by the same study. ${ }^{10}$ It was observed that OSMF developed on one side of the buccal vestibule where they kept and chewed betel and tobacco products while the other side was normal. ${ }^{4}$ There is no 


\begin{tabular}{|c|c|c|}
\hline OUTCOME & FREQUENCY & PERCENT \\
\hline Improved without surgery & 252 & 90.6 \\
\hline Improved after Laser Excision & 14 & 5.0 \\
\hline Cancer (Malignant Transformation)* & 12 & 4.3 \\
\hline Death & 0 & 0.0 \\
\hline
\end{tabular}

Table 3. Prognosis/outcome of OSMF cases $(n=278)$, *: confirmed by Biopsy and Histopathological examination

effective treatment for OSMF. ${ }^{3}$ In OSMF, the incidence of oral cancer is 7.6 per cent for a median 10-year follow-up period. Risk markers for malignant transformation in OSMF include epithelial dysplasia, and p53 tumor suppressor gene mutations. ${ }^{11}$ In normal patients mouth opening is more in males than females. ${ }^{7}$ However, there was no difference in mouth opening between males and females in diseased condition (OSMF). Early and timely diagnosis and treatment is important for good prognosis of the disease.

\section{CONCLUSION}

Thimphu district had the highest proportion of OSMF cases and was almost equally distributed among genders. Over $90 \%$ of the patients reported improvement without surgery while the malignancy transformation rate was $4.3 \%$. The study recommends conducting screening in districts with high burden of OSMF cases for early diagnosis and treatment.

Acknowledgement: The authors would like to thank all staffs of dental department for their help and management of the hospital for permitting us to conduct this study.

\section{REFERENCES}

1. Das M, Manjunath C, Srivastava A, Malavika J, Ameena MVM. Epidemiology of Oral Submucous Fibrosis: A Review. Int J Oral Health Med Res 2017;3(6):126-9.

2. Rao NR, Villa A, More CB, Jayasinghe RD, Kerr AR, Johnson NW. Oral submucous fibrosis: a contemporary narrative review with a proposed inter-professional approach for an early diagnosis and clinical management. J Otolaryngol Head Neck Surg. 2020;49:3. https://doi.org/10.1186/s40463-020-0399-7 3. Kale MV, Gaikwad NS. Oral submucous fibrosis: a study of qualitative and analytical treatment using intralesional injections: placental extract versus combination of steroid with hyaluronidase. Int J Otorhinolaryngol Head Neck Surg. 2020;6(7):1320-5. http://doi.org/10.18203/issn.2454-5929.ijohns20202786
4. Ahmad MS, Ali SA, Ali AS, Chaubey KK. Epidemiological and etiological study of oral submucous fibrosis among gutkha chewers of Patna, Bihar, India. J Indian Soc Pedod Prev Dent. 2006;24(2):84-9. http://doi.org/10.4103/o9704388.26022 .

5. Srivastava R, Jyoti B, Pradhan D, Siddiqui Z. Prevalence of oral submucous fibrosis in patients visiting dental OPD of a dental college in Kanpur: A demographic study. J Family Med Prim Care. 2019;8:2612-7.

http://doi.org/10.4103/jfmpc.jfmpc_465_19

6. Gondivkar SM, Gadbail AR, Sarode SC, Gondivkar RS, Patil S, Gaikwad RN, et al. Treatment outcomes of laser therapy in oral submucous fibrosis-a systematic review. J Oral Biol Craniofac Res. 2020;10(3):253-8. http://doi.org/10.1016/j.jobcr.2020.05.004

7. Khare N, Patil SB, Kale SM, Sumeet J, Sonali I, Sumeet B. Normal mouth opening in an adult Indian population. Journal of Maxillofacial and Oral Surgery. 2012;11(3):309-13. http://doi.org/10.1007/s12663-0120334-1

8. Li X-Y, Jia C, Zhang Z-C. The normal range of maximum mouth opening and its correlation with height or weight in the young adult Chinese population. J Dent Sci. 2017;12(1):56-9. http://doi.org/10.1016/j.jds.2016.09.002.

9. Passi D, Bhanot P, Kacker D, Chahal D, Atri M, Panwar Y. Oral submucous fibrosis: Newer proposed classification with critical updates in pathogenesis and management strategies. Natl J Maxillofac Surg. 2017;8(2):89-94.

http://doi.org/10.4103/njms.NJMS_32_17

10. Chourasia NR, Borle RM, Vastani A. Concomitant Association of Oral Submucous Fibrosis and Oral Squamous Cell Carcinoma and Incidence of Malignant Transformation of Oral Submucous Fibrosis in a Population of Central India: A Retrospective Study. J Maxillofac Oral Surg. 2015;14(4):902-6. http://doi.org/10.1007/s12663-015-0760-y

11. Wan K, Kademani D. Oral Epithelial Dysplasia, Improving Outcomes in Oral Cancer. In: Kademani K. 
Improving Outcomes in Oral Cancer. $1^{\text {st }}$ ed. Springer, Cham;2020,pp:1-12. https://doi.org/10.1007/978-3-03030094-4.

Cite this article as:

Tamang PS, Bajgai GP, Pokhrel HP. Distribution of Oral Submucous Fibrosis Cases and Malignant Transformation Rate among Bhutanese Patients Treated at Jigme Dorji Wangchuck National Referral Hospital, Bhutan. Int Healthc Res J. 2021;4(12):OR7-OR1o. https://doi.org/10.26440/IHRJ/0412.03391

AUTHOR AFFILIATIONS: ( ${ }^{*}$ Corresponding Author)

1. Department of Dentistry, Jigme Dorji Wangchuck National Referral Hospital, Thimphu, Bhutan.

2. Gidakom Hospital, Ministry of Health, Thimphu, Bhutan (https://orcid.org/oooo-0003-4421-7378).

Source of support: Nil, Conflict of interest: None declared
Contact Corresponding Author at: hari88pokhrel[at]gmail[dot]com 